\author{
Military Technical College \\ Kobry El-Kobbah, \\ Cairo, Egypt.
}

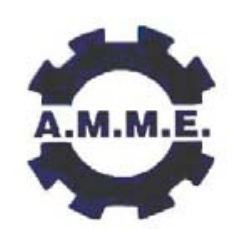

\title{
EFFECT OF BOLT SCATTER ON DIFFERENT SIZES OF GASKETED BOLTED FLANGE JOINTS: A COMPARATIVE F.E. STUDY
}

\author{
$13^{\text {th }}$ International Conference \\ on Applied Mechanics and \\ Mechanical Engineering.
}

ABID $M^{*}$

\begin{abstract}
The performance of gasketed bolted flange joint depends on the proper joint assembly. During gasketed joint assembly, joint relaxation is a known phenomenon which is concluded due to the bolt scatter. Non-uniform gasket stress is concluded due to the bolt scatter using torque control method and due to the presence of the elastic interaction and flange deformation. In this paper, flange bending stress, flange rotation, bolt bending, stress variation at gasket and centring ring of the gasketed flange joints for class $900 \#$ and different sizes from $0.5-24$ inch is analyzed during bolt up and internal pressure loading for comparative study. Bolt scatter and overall joint relaxation behaviour is discussed in detail for different sizes.
\end{abstract}

\section{KEY WORDS}

Gasketed, strength, sealing, bolt up, bolt bending, yielding

\section{NOMENCLATURE}

\begin{tabular}{ll} 
bd & bolt diameter \\
bhd & bolt hole diameter \\
bcd & bolt circle diameter \\
fod & flange outside diameter \\
fh & flange ring height \\
gcringod & gasket centring ring outside diameter \\
gid & gasket inside diameter \\
gsringid & gasket seal ring inside diameter \\
gsringht & gasket seal ring height \\
gsringod & gasket seal ring outside diameter \\
gth & gasket centring ring heighth \\
hubht & hub height \\
pid & pipe inside diameter \\
\hline
\end{tabular}

* Associate Professor, Faculty of Mechanical Engineering, Ghulam Ishaq Khan Institute of Engineering Sciences and Technology, Topi, Pakistan 


$\begin{array}{ll}\text { pod } & \text { pipe outside diameter } \\ \text { sh } & \text { shoulder height } \\ \text { sod } & \text { shoulder outside diameter } \\ \text { jh } & \text { joint height }\end{array}$

\section{INTRODUCTION}

In most of the industrial applications, optimized flanged pipe joint is the main concern especially using gasketed joints. The major problems faced are the bolt and gasket damage, flange yielding and leakage during bolt up and operating conditions. Detailed experimental and numerical studies are carried out by [1-14] highlighting the above mentioned problem associated with the gasketed flange joints. Behaviour of the gasketed flange joints for class $900 \#$ and different sizes ranging from $0.5-24$ inch is analyzed during bolt up and internal pressure loading for comparative study using detailed 2-dimensional finite element analysis (FEA). Surface yielding at the hub of the flange (i.e. $20 \%$ of the hub thickness) is allowed as the flanges are observed overdesigned. In addition to avoid the effect of stress concentration at the flange shoulder corner (raised face) nodes at this corner are also neglected. This is aimed to achieve the required gasket seating stress and utilise the bolt strength by increasing the applied bolt up load. From finite element analysis, for a few sizes i.e. 14 to 24 inch the required gasket seating stress $(68 \mathrm{MPa})$ recommended by the gasket supplier is achieved only at bolt up which further is reduced under internal pressure loading. The bolt load applied in FEA is ideal and axi-symmetric and is applied as a ring whereas it is not the case in real world situation such as in the experimental work.

\section{FLANGE JOINT GEOMETRY AND ALLAWABLE STRESSES}

Flange, pipe and gasket dimensions are selected as per British Standards [15, 16]. Based on the actual industrial applications mostly used, in this present study it is decided to model the flanges of class $900 \#$ without raised face. During this FEA study, gaskets are modelled as a solid ring/plate of stainless steel material. This is considered based on the gasket supplier's recommendation that proper sealing from the gasket is achieved when its seal ring portion is compressed close to the centring ring dimensions. Therefore during bolt up, gasket is compressed up to the required gasket seating stress; its raised sealing portion is compressed equal to the centring ring thickness, hence it is modelled as a solid plate. Allowable stresses for flange, bolt and gasket are given in Table-1 [17]. Gasket minimum seating stress is taken as $68 \mathrm{MPa}$ (as per gasket manufacturers).

\section{FINITE ELEMENT MODELLING}

Previous work by Spence et al. [18] and Nash et al. [19], showed the viability of a twodimensional axi-symmetric model, for what is essentially a three-dimensional component. In neglecting the holes in the flange and the presence of individual bolts round the flange, the system can be considered as a continuous bolt ring located at the bolt centre and running round the circumference of the bolt circle. The ANSYS [20] finite element code is employed throughout this work. Fully parametric finite element models are used throughout so that the time involved in building the scaled geometry 
models of other different sizes is minimised. ANSI flange drawing with different parameters are shown in Fig. 1.

\section{Element Selection and Mesh}

Since flange, bolt and gasket stresses are the required outputs from this study, it is necessary to use two classes of element. Solid element PLANE82 to model the solid entities and contact element CONTACT48 to measure contact pressure or stress variation between the mating surfaces are used. In order to ensure accurate results, a reasonably refined mesh is applied in the regions of interest such as at the hub-pipe, hub-flange intersections and at the raised face corner.

\section{Boundary Conditions}

Internal pressure is applied at the inside diameter, and the loading due to the head is directly applied as nodal forces across the wall of the pipe [5]. The flanges are free to move in either the axial or radial direction and rotate, providing the exact behaviour of the stresses in the flange and the bolt. Symmetry plane is constrained in both the axial and radial directions. Due to the gap between the flanges, internal pressure is also applied on the gasket inside diameter as well as on the flange shoulder in the gap. The gasket is constrained in the radial direction to prevent it moving radially since, in practice, it is located interior to the bolts. The bolt is constrained at the mid diameter in the radial direction as they cannot move in this direction within the bolt hole. An axial displacement is applied on the bottom nodes of the bolt shank which is progressively optimised by sequential iteration, to obtain the required pre-stress. Finite element model, with applied boundary conditions is shown in Fig. 2 for flange size 4 inch, class $150 \#$.

\section{Analysis Solution}

During analysis, following multi-load step procedure is used.

- Contact between flange top surface and washer bottom, flange bottom and gasket/symmetry plate is initiated by applying a small initial axial displacement.

- Axial displacement equivalent to the nominal pre-load of about $50 \%$ (350MPa) of the yield strength of the bolt is applied. Actually bolt up load is limited by the gasket supplier's recommended values to avoid gasket crushing and even from experimental results given in [4] these are observed for class 900 and 4 inch size limited to $30-35 \%$ of the yield strength of bolt material. This results in improper sealing. In order to utilize proper bolt strength and for more tightness to avoid leakages bolt up-to $50 \%$ is applied for optimization.

- Internal pressure is applied for each corresponding size of the joint as per BS1560; Sec 3.1.

\section{Optimisation Criteria and Procedure}

During bolt up, pre-stress up to $50 \%$ of the yield of the bolt is optimized, neglecting yielding in the hub-flange fillet, as the target is to achieve required pre-load mentioned above. During the pressure load application, optimisation is performed by allowing up to $20 \%$ surface yielding at hub-flange fillet as the target is to achieve required gasket seating stress. 


\section{RESULTS AND DISCUSSION}

In order to understand the behaviour of the flange joint components, exaggerated plots showing flange yielding and flange rotation is shown in Fig. 3a-b, and bolt bending and gasket crushing is shown in Fig. 4a-b during internal pressure loading.

\section{Flange Stress}

During bolt up of $50 \%$ of the yield of the bolt, yielding at hub-flange fillet and at the inside diameter along the hub-flange fillet is observed for most sizes. However, the maximum stress noted was within the range of the yield stress of the flange material. Flange size 0.5 and 0.75 inch showed the yielding during pre-stress application. During internal pressure loading in the allowable elements, bolt pre-loading was optimized to control stress within the allowable stress limit. Due to this, bolt stress was reduced to about half of the required bolt pre-stress. Stress intensity plot showing yielding at different locations with the depth of yielding for 4 inch flange joint size is shown in Fig. $3 a$ and almost similar trend is observed in all other sizes.

\section{Bolt stress}

Bolt bending is obvious from the stresses at the inside and outside node of the bolt during bolt up and internal pressure loading [Fig. 5]. In general, similar bolt bending trend is observed for all the three classes. Stress at the inside diameter for all the bolts is more than $345 \mathrm{MPa}$. At the outside node of the bolts, it was found in the range of 60 to $70 \%$ of the stress at the inside node for class $2500^{\#}, 82$ to $85 \%$ of the stress at the inside node for class $900^{\#}$. For the class $150^{\#}$, stress variation at the inside and outside node is very large. In some cases it was observed more than the yield stress of the bolt material at the inside node. Bolt stress is decreased after the application of internal pressure as the main reason is to avoid the flange yielding as discussed earlier. This also resulted in reduced flange rotation with slight stress increase at the inside node. For the flanges of size 0.5 and 0.75 inch, the stress at the outside node is noted about 9 to $10 \%$ of the inside node. For the flange sizes 1-8 inch it is noted between 25 to $35 \%$ of the inside node. For the sizes between, 10-24 inch, stress at the out side node noted is about 1 to $10 \%$ of the inside node. An exaggerated plot showing SI distribution and bolt bending is shown in Fig. 4 a.

\section{Flange Rotation}

For class $900 \#$, a slight decrease in flange rotation is observed for flange size of 0.75 and 1 inch. An obvious flange rotation variation is noted for sizes 1.5 to 6 -inch. However, up to 6 inch flange size, difference in rotation at bolt up and internal pressure loading is almost negligible. For sizes 6 inch and onwards increase in flange rotation is observed with continuously increasing flange rotation difference. Overall, flange rotation varied from 0.05-0.08 degree under bolt up and 0.05-0.10 degree under internal pressure loading for flange size $0.5-24$ inch size. In general, flange rotation increased with an increase in flange size and is shown in Fig. 6 for all the different flange sizes.

Average stress in the bolt is almost the same as the required pres-stress in the bolt for class $900 \#$ and $2500 \#$. For class $150^{\#}$, for some sizes, it reduced under internal 
pressure loading resulting in reduced flange rotation. This is concluded due to the reduced bolt pre-stress to control yielding in the allowed elements.

\section{Gasket stress}

For the gasketed flange joint, to be leak free, achievement of the required gasket seat stress is considered very important. From gasket contact stress variation results in Fig. 7 at bolt up, gasket stress at the inside diameter of the gasket is observed much less $(0-20 \mathrm{MPa})$ than the required seating stress up to flange size of 4 inch. For flange size 6-14 inch, it rapidly increased and then from 16-24inch, it was noted more than the required seating stress. At the outside diameter, stress is observed close to the required seating stress up to flange size of 1.5 inch and then decreased to 40MPa up to flange size of 18 inch. It then again increased close to the required seating stress for sizes 20 and 24 inch. Under applied internal pressure loading, gasket stress at the inside diameter decreased further and remained almost zero up to the flange size of 12 inch. It increased to 30MPa for flange sizes 14-18 inch and is observed close to the required for 20 and 24 inch sizes. At the outside diameter, similar trend with slightly decreased stress as under bolt up is observed. Exaggerated deformed gasket plot for flange size 4 inch is shown in Fig. 4b.

\section{Stress in the centring ring of gasket}

The gaskets used in the flange joints are spiral wound gaskets. After the compression of the gasket-raised portion that serves the purpose for the seal, flanges are exposed to the centring ring. Any further overloading on the joint will cause the crushing or flattening of the centring ring. From Fig. 8, stress variation of $(0-20 \mathrm{MPa})$ during bolt up at the inside diameter of the centring ring is observed, which reduced further to (0$10 \mathrm{MPa}$ ) under internal pressure loading. This is concluded due to the load taken by the gasket seal ring portion first. Whereas, due to the flange rotation, although stress at the outside diameter of the centring ring can be different, however due to the free edge these are considered of no much importance.

\section{CONCLUSIONS}

Based on detailed parametric FEA study, following are concluded;

- From bolt bending and stress variation, dynamic mode-of-load is concluded. Overall, it increased with the increase in flange size for all the three classes.

- Even by increasing the bolt up to about $50 \%$ of the bolt yield, and machining of the raised face, the minimum required gasket stress seating stress for proper joint sealing is not achieved and can be increased more for proper sealing for all flange classes.

- Although machining of the raised face for flanges of class 900\# has affected, but still a reasonable flange rotation, flange yielding, bolt bending and possible gasket crushing and possible leakage from the joint is concluded. Presence of raised face on the flange face will provide worst effect on the strength and sealing of different flange sizes ranging from $0.5-24$ inch.

- Flange yielding in some cases is also observed at the inside diameter along hub height. Although $20 \%$ surface yielding is allowed in the present FEA study whereas in actual applications this is not the case. 
- Bolt up applied as axi-symmetric i.e. equal in each bolt by applying a displacement not the torque is an ideal conditions, which in actual practice is not the case due to many factors. Similarly gasket was considered as a solid plate, whereas, for more accurate analysis it is important to model its non-linear behaviour and is recommended.

- Based on this comparative study, even for the flanges of same class but with different dimensional inconsistency, for better joint performance optimized applied pre-stress is considered important and is recommended.

- Use of proper gasket configuration and material for proper joint performance is observed important and recommended for consideration.

- No bolt relaxation in the joint is considered as a major assumption is in the present study. Hence for more realistic joint behaviour, a detailed 3D FE study is recommended.

Even after optimisation, it is concluded that some geometries may prove successful but most may leak due to poor geometric proportioning

\section{REFERENCES}

1. Webjörn, J. "Flange Design in Sweden". Proceedings of the Petrochemical Mechanical Engineering Conference, American Society of Mechanical Engineers, Philadelphia PA, September. pp 17-20. (1967).

2. Webjörn, J. "The Bolted Joint - a Series of Problems". Linköping Studies in Science and Technology, Dissertation No. 130. (1985).

3. Power, D J., "A Study of Conventional and Unconventional Flanged Pipe Joint Styles Using Non Linear Finite Element Analysis Techniques". M.Phil. Thesis. 1997.

4. Abid, M. "Experimental and Analytical studies of conventional (gasketed) and unconventional (non gasketed) flanged pipe joints (with special emphasis on the engineering of 'joint strength' and 'sealing')". PhD Thesis. University of Strathclyde, Glasgow UK, (2000).

5. Abid, M., Nash, D. H. "Comparative study of the behaviour of conventional gasketed and compact non-gasketed flanged pipe joints under bolt up and operating conditions". International Journal of Pressure Vessels and Piping, 80, pp 831-841. (2004).

6. M. Abid, "Determination of gasketed and non-gasketed flanged pipe joint's capacity subjected to combined loading: An experimental approach" International Journal of Mechanics and Materials in Design. DOI 10.1007/s10999-005-0519-6. 2: 35-47. (2005).

7. M. Abid, D. H. Nash, "Structural Strength: Gasketed Vs Non-gasketed flange joint under bolt up and operating condition" International Journal of Solids and Structures. IJSS 05-217. Pp. 1-14. (2005).

8. Muhammad Abid, "Comparative Modal Analysis of Gasketed and Non-Gasketed Bolted Flange Joints", Computer Aided Design and Manufacturing: A Global Perspective (CCADM2005), April 8-9, Patiala, India. pp. 1-12. (2005).

9. Muhammad Abid, "Determination of safe operating conditions for gasketed flange joint under combined internal pressure and temperature" International Journal of Pressure Vessels and Piping. IPVP2654. pp. 1-9. (2006).

10. Muhammad Abid, 'Stress variation in flange of a gasketed flanged pipe joint during bolt up and operating conditions' International Journal of Science and Technology, Scientia Iranica Vol. 13-3 pp. 303-309. (2006). 
11. Muhammad Abid, Baseer Ullah, "3-D Nonlinear Finite Element Analysis of Gasketed Flange Joint under Combined Internal Pressure and Different Temperatures" Journal of Engineering Mechanics by ASCE. Vol. 133/2 pp. 1-8. (2006).

12. M. Abid, D.H.Nash, "Relaxation behaviour of a gasketed and non-gasketed bolted flanged pipe joint - A Comparative Study". WSEAS Transaction on Applied and Theoretical Mechanics'.Issue-2, Vol. 1pp. 239-246. (2006).

13. M. Abid, D. H. Nash, 'Bolt bending behaviour in a bolted flanged pipe joint: A comparative study', ASME Pressure Vessel and Piping Conference, Hyatt Regency Vancouver, Vancouver, British Columbia, Canada, July 23-27. pp. 1-9. (2006).

14. M. Abid, D.H.Nash, "Joint relaxation behaviour of gasketed bolted flanged pipe joint during joint assembly", Submitted to the 2nd WSEAS International Conference on Applied and Theoretical Mechanics (MECHANICS'06) Venice, Italy, November 20-22. pp. 319-325. (2006).

15. British Standard Institution, London, UK. "Circular Flanges for Pipes, Valves and Fittings, BS1560: Section 3.1". (1989).

16. British Standard Institution, London, UK. "Dimensions of Gaskets for Flanges to BS1560, BS7076: Part 1". (1989).

17. American Society of Mechanical Engineers, New York, USA. "ASME Boiler and Pressure Vessel Code, Section II, Part D". (1998).

18. Spence, J., Macfarlane, D. M. and Tooth, A. S. "Metal-to-Metal full face taper hub flanges: finite element model evaluation and preliminary plastic analysis". Proc. Instn. Mech. Engrs. 212 (E), pp 57-69. (1998).

19. Nash, D. H., Spence, J., Tooth, A. S., Abid, M., and Power, D. J. "A parametric study of metal-to-metal full faces taper hub flanges". Intl. Journal of Pressure Vessels and Piping, 77 (13), pp 791-798. (2000).

20. ANSYS Inc., "ANSYS Elements Manual, Seventh Edition”. (2004).

Table 1: Material Properties

\begin{tabular}{|c|c|c|c|c|}
\hline Part & $\begin{array}{c}\text { Young's } \\
\text { Modulus } \\
\text { E (MPa) }\end{array}$ & $\begin{array}{c}\text { Poisson' } \\
\text { s ratio } \\
(\mathrm{u})\end{array}$ & $\begin{array}{c}\text { Design } \\
\text { Stress } \\
\text { (MPa) }\end{array}$ & As per code [17] \\
\hline $\begin{array}{c}\text { Flange \& } \\
\text { Pipe }\end{array}$ & 173058 & 0.3 & 248 & $\begin{array}{c}\text { ASTM A350 LF2 or } \\
\text { A105 }\end{array}$ \\
\hline Bolt & 168922 & 0.3 & 723 & ASTM SA193 B7 \\
\hline Gasket & 164095 & 0.3 & 207 & ASTM A182 F316 \\
\hline
\end{tabular}




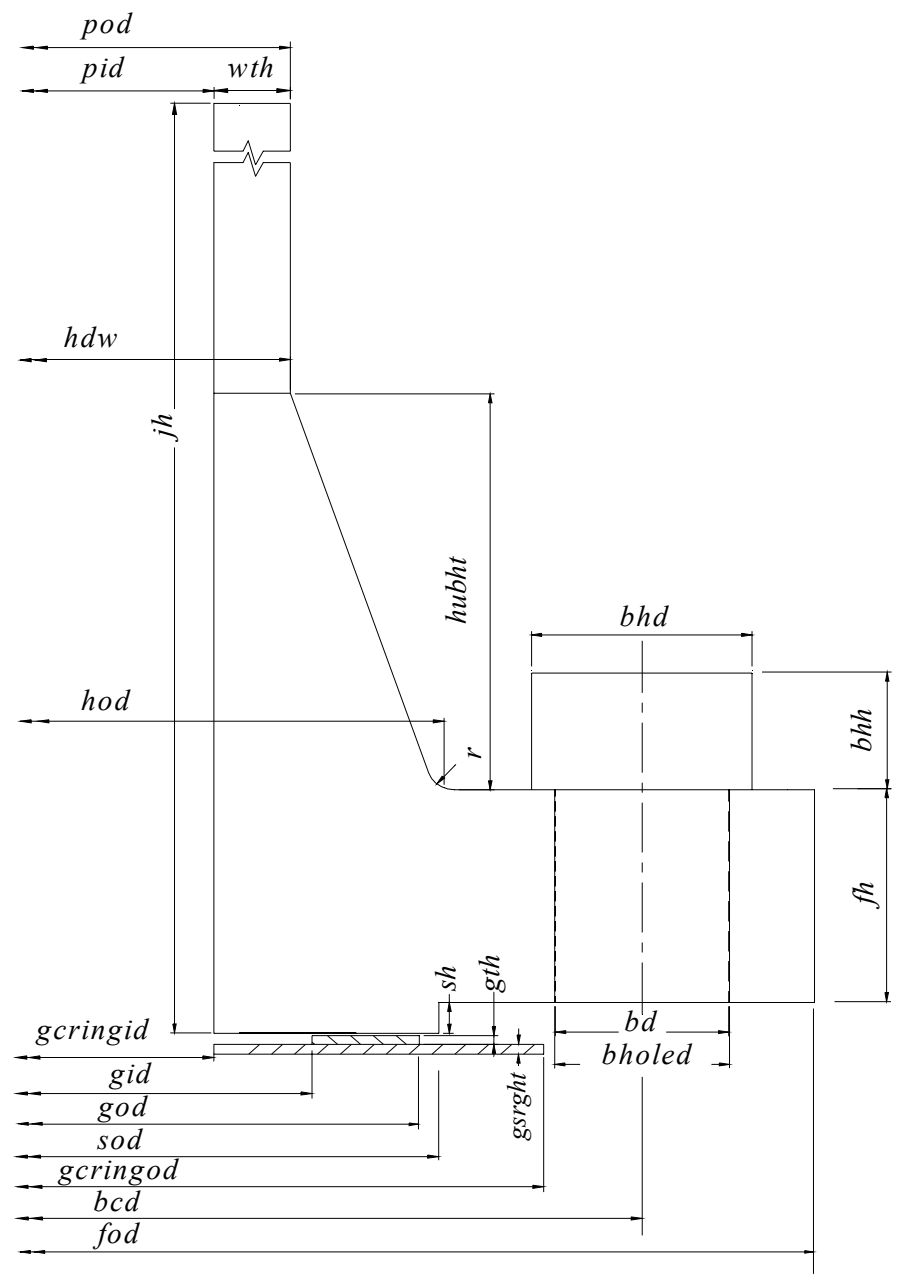

Figure 1: ANSI Flange showing design parameters

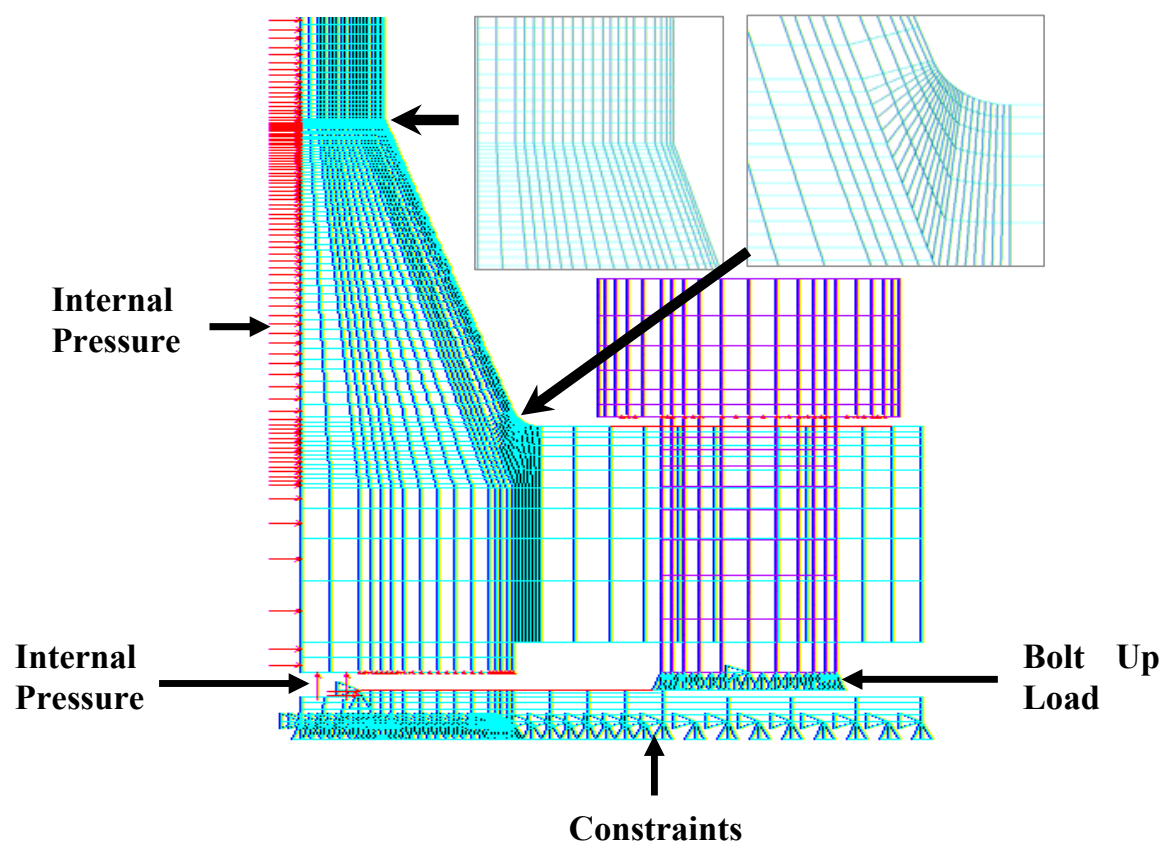

Figure 2: Geometry, Mesh and Applied Boundary Conditions 


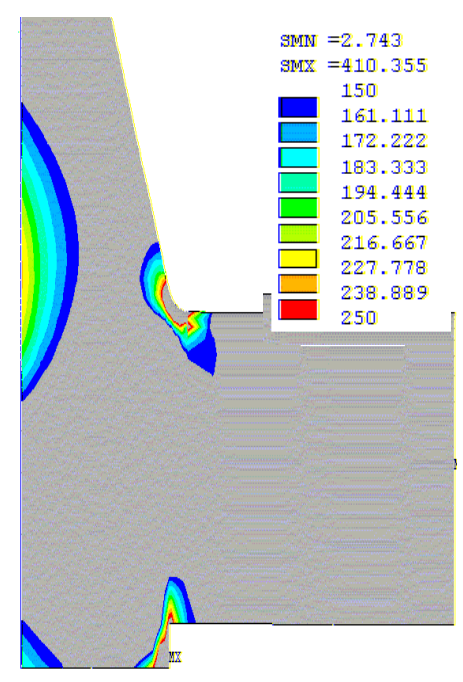

(a)

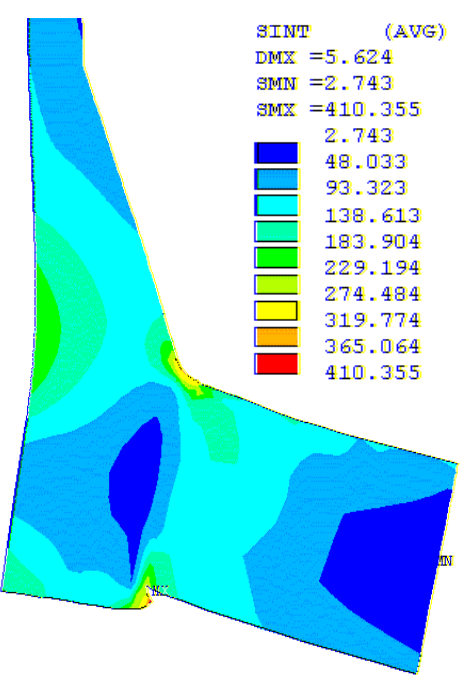

(b)

Figure 3: (a) SI plot showing the location and the depth of yielding, (b) Exaggerated plot.

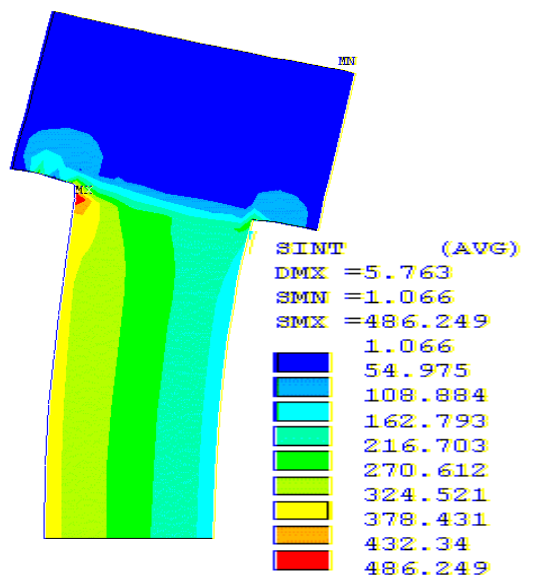

(a)

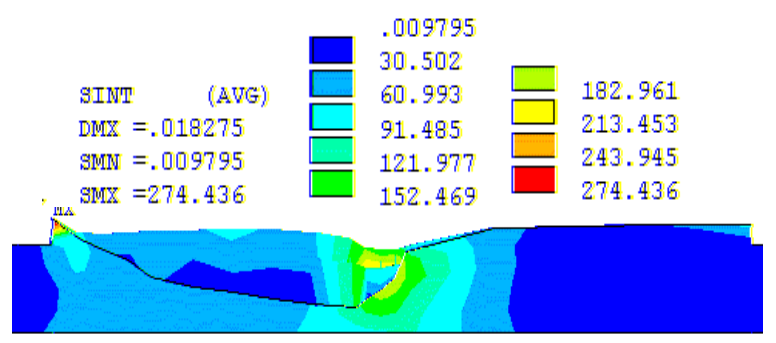

(b)

Figure 4: Exaggerated plot showing; (a) Bolt bending and SI distribution, (b) gasket deformation and SI distribution

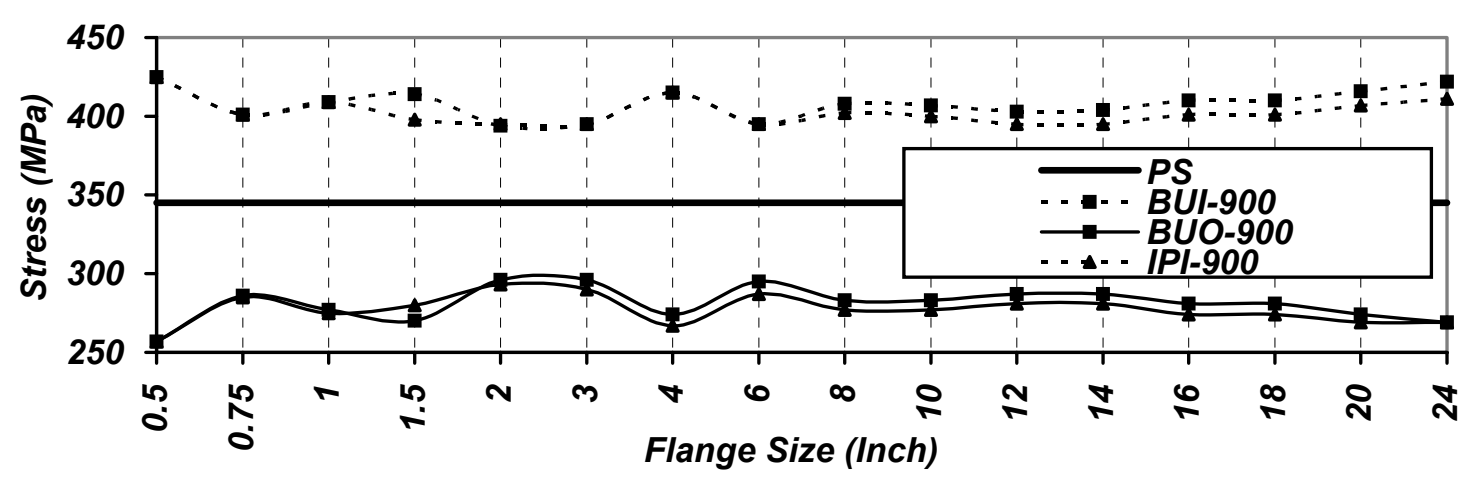

Figure 5: Bolt bending stress variation for different flange sizes 


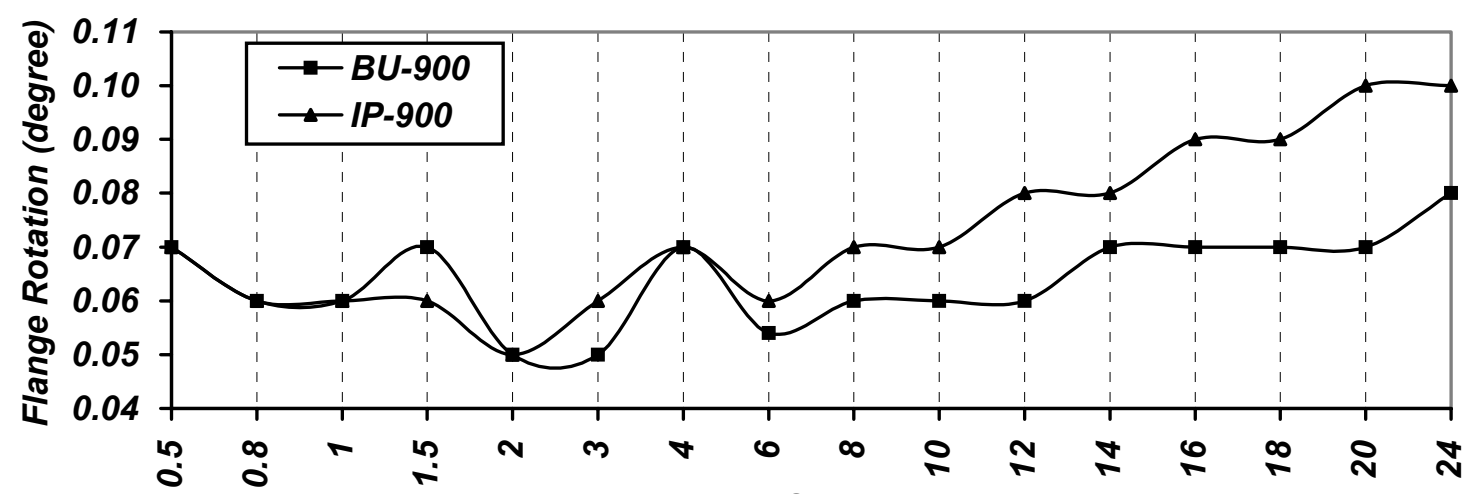

Flange Size (Inch)

Figure 6: Flange rotation during bolt up and IP

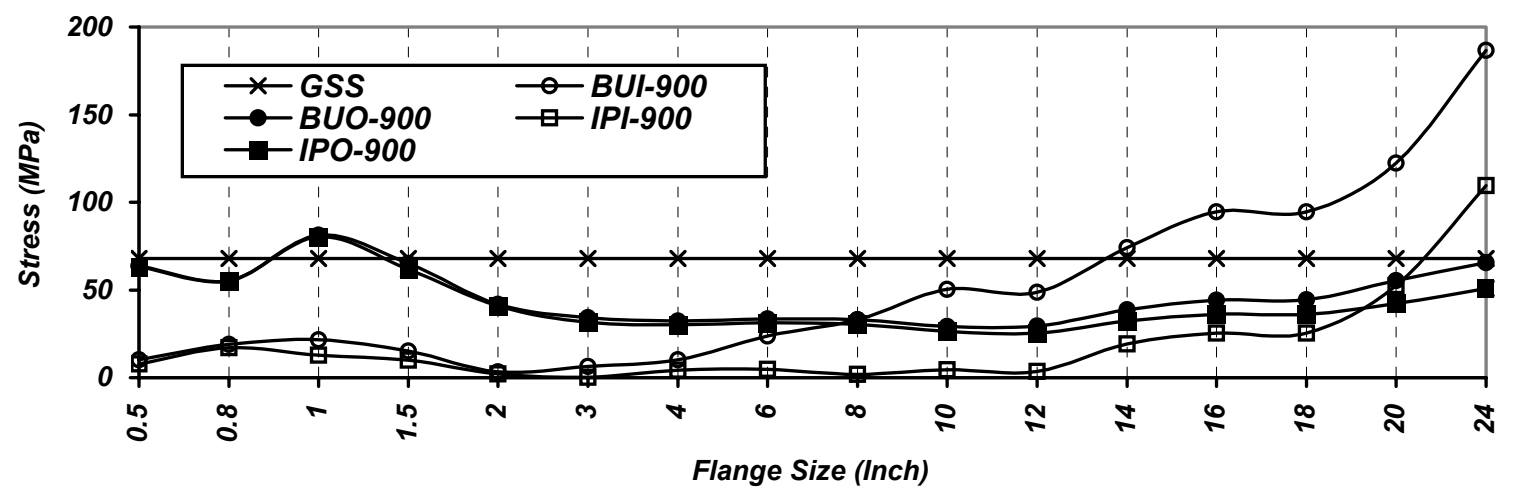

Figure 7: Gasket stress variation

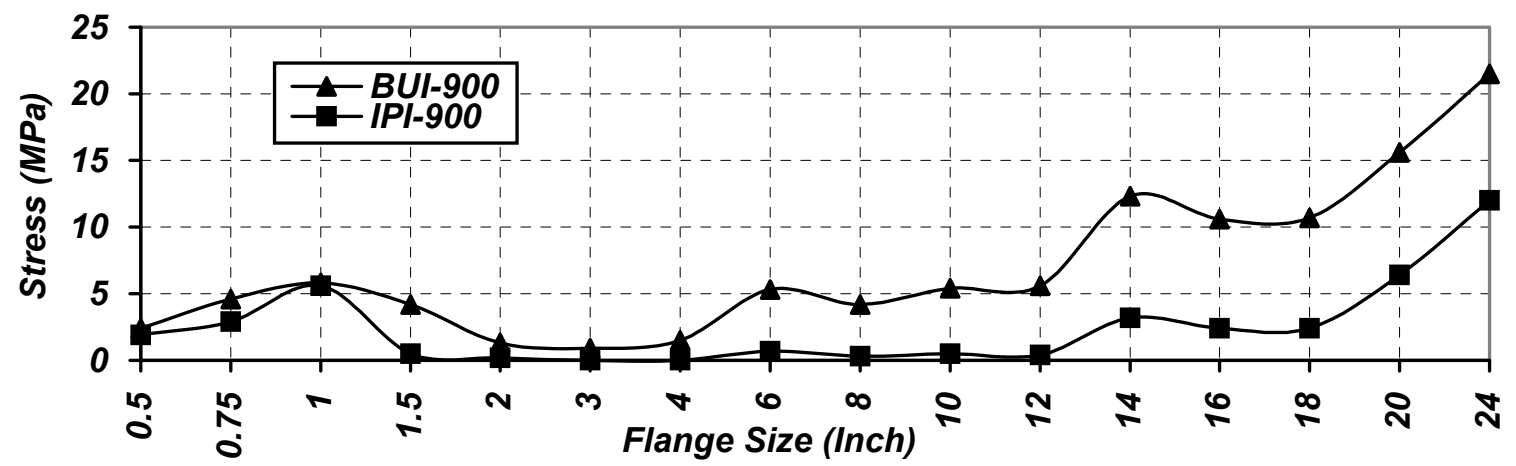

Figure 8: Centring Ring stress variation at the inside nodes during bolt up and IP. 